\section{El Sequeral (Calahorra, La Rioja). Investigación fotogramétrica y arqueología}

\author{
M. a Asunción Antoñanzas*, Pilar IguÁcel de la CruZ*, \\ Ane Lopetegui Galarraga**, José Manuel Valle Melón** \\ * Universidad de La Rioja \\ ** Unidad Asociada CSIC/Universidad del País Vasco. Grupo de Arqueología \\ Tardoantigua y Medieval. Arqueología de la Arquitectura (GATMAA)
}

\begin{abstract}
Resumen
Durante los trabajos de excavación e investigación en un torreón romano en Calagurris lulia (Calahorra, La Rioja), la utilización de la información suministrada por la topografía y la fotogrametría digital ha permitido la elaboración de una base de datos geométrica del yacimiento. El enlace de estos datos geométricos con aquellos puramente arqueológicos ha tenido como resultado la creación de un Sistema de Información Patrimonial que propicia la sistematización del registro de lo excavado, facilitando su posterior lectura y la reinterpretación de todos los niveles arqueológicos significativos.
\end{abstract}

Palabras Clave: Murallas romanas, Fotogrametría, Documentación topográfica, Bases de datos, Sistema de Información Patrimonial.

\footnotetext{
Abstract

During excavation and research work in a Roman tower in Calagurris Iulia (Calahorra, La Rioja), the use of information provided by digital photogrammetry and topography made it possible to draw up a geometric database of the site. The combination of this geometric data with purely archaeological data has led to the creation of a Heritage Information System, creating favourable conditions for the systemization of a register of what is excavated, facilitating later reading and the reinterpretation of all significant archaeological levels.
}

Key words: Roman walls, Photogrammetry, Topographic documentation, Databases, Heritage Information System.
El yacimiento de El sequeral se encuentra ubicado en el casco histórico de Calahorra (La Rioja). La excavación efectuada durante la campaña del año 2000 ha ocupado la totalidad de la cuesta que, sin asfaltar, comunicaba las llamadas Murallas Altas con Murallas Bajas ${ }^{1}$.

\section{METODOLOGÍA}

\section{Recogida de la información}

La metodología empleada consta de una primera fase de recogida de información, en sus dos vertientes, la arqueológica y la topográfica, que se desarrolla durante la realización de los trabajos de campo.

Para una mejor recuperación de sistemas de estructuras y estratos de tierra lo más complejos y continuos posibles (CARANDINI, 1997: 53), se ha optado por una excavación en área a lo largo de toda la superficie del yacimiento.

Asimismo se ha elegido el método estratigráfico desarrollado por Harris a través del cual se identifican las distintas unidades estratigráficas y sus relaciones de anterio-posterioridad (BARKER, 1977; HARRIS, 1991), que ayudan a desentrañar el proceso de formación del yacimiento.

El registro geométrico de las diferentes unidades estratigráficas aparecidas a medida que avanzaba la excavación ha sido ejecutado de dos formas diferentes, dependiendo de su complejidad:

—Las unidades estratigráficas de geometría sencilla fueron registradas por métodos topográficos.

—El registro de unidades estratigráficas de geometría compleja fue realizado por métodos fotogramétricos. (Fig. 1)

\section{Tratamiento de la información}

De forma paralela a los trabajos de campo, en el laboratorio, se ha creado una base de datos relacional específica para la documentación arqueológica. Dicha base de datos engloba registros de yacimientos, unidades estratigráficas, hallazgos e imágenes generadas — croquis, dibujos a escala y fotografías- disponiendo en soporte informático de la posibilidad de localización y extracción de todo tipo de información, estructurándola por búsquedas lógicas de interés para el investigador. (fig. 2)

A partir de los datos topográficos obtenidos en campo (pares de fotografías, coordenadas de puntos de apoyo y

\footnotetext{
1 Su excavación ha formado parte del proyecto que llevaba por título «Recuperación, investigación y musealización del casco histórico de $\mathrm{Ca}$ lagurris Iulia (Calahorra, La Rioja)». En dicho proyecto, financiado con Fondos FEDER, han estado involucradas las Universidades de La Rioja, el País Vasco y la Región de Murcia. Y su principal objetivo fue el estudio, conocimiento, conservación y musealización del Patrimonio Histórico de la ciudad romana de Calagurris Iulia.
} 


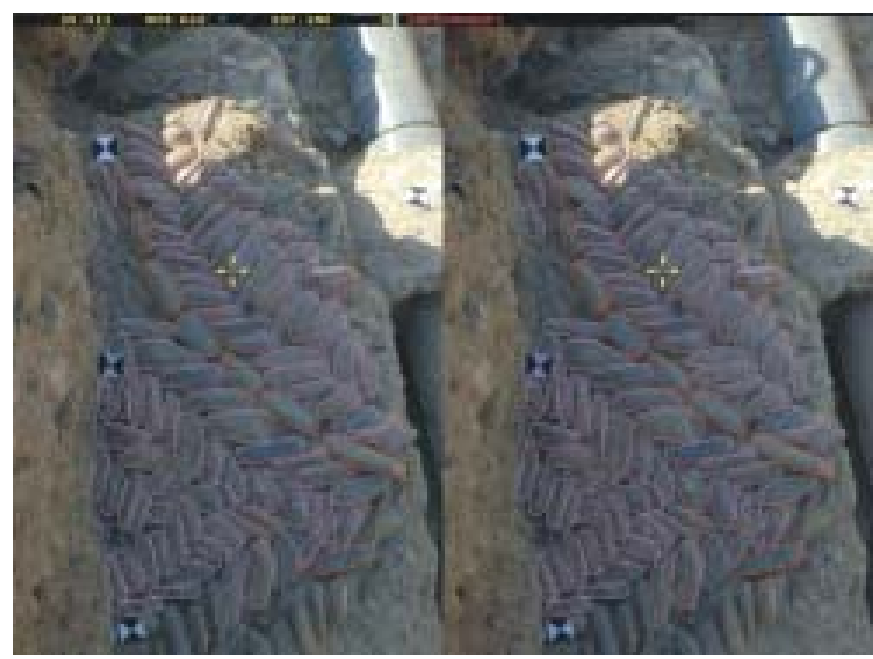

Fig. 1. Restitución fotogramétrica

coordenadas de puntos que definen los objetos no fotografiados) se procede, mediante el consiguiente trabajo de gabinete, a la obtención de los documentos que formarán parte de la base de datos geométrica de cada uno de los yacimientos. En esta base de datos geométrica aparecerán representadas las unidades estratigráficas de forma que puedan ser utilizadas para el análisis arqueológico del yacimiento y constará de diversos tipos de representaciones: plantas, alzados, desarrollos, secciones... (Fig. 3).

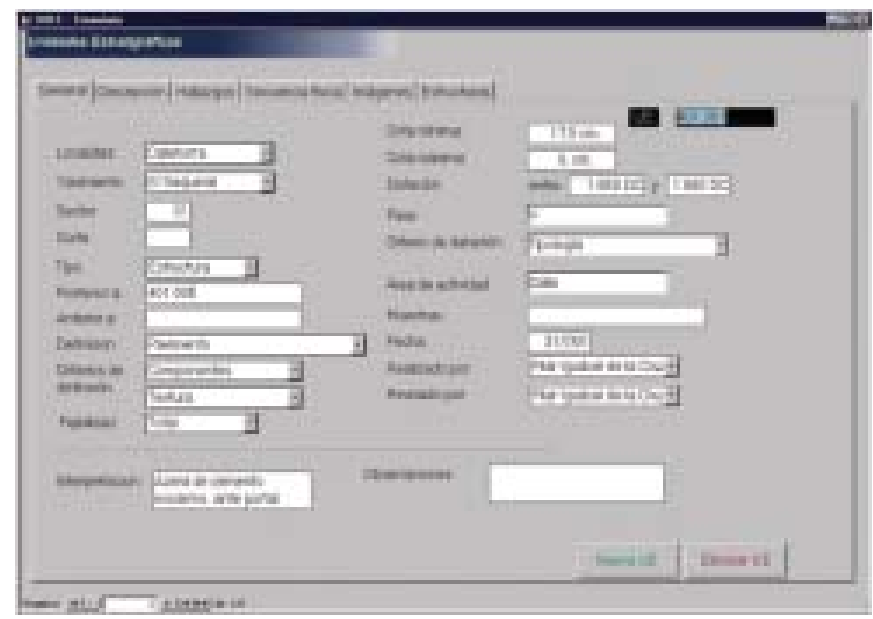

Fig. 2. Entrada de información en la base de datos

\section{Análisis de la información}

El enlace entre bases de datos supone un paso adelante en el desarrollo de una metodología de gestión de la información. La integración de la información gráfica y la información almacenada en la base de datos se realiza a través de un Sistema de Información Patrimonial. Dicho sistema de información permite que las consultas tengan un reflejo directo en la representación gráfica; asimismo y de manera inversa, el sistema ofrece la posibilidad de seleccionar un objeto en la pantalla y, a través de él, acceder a la información arqueológica correspondiente. (Fig. 4)

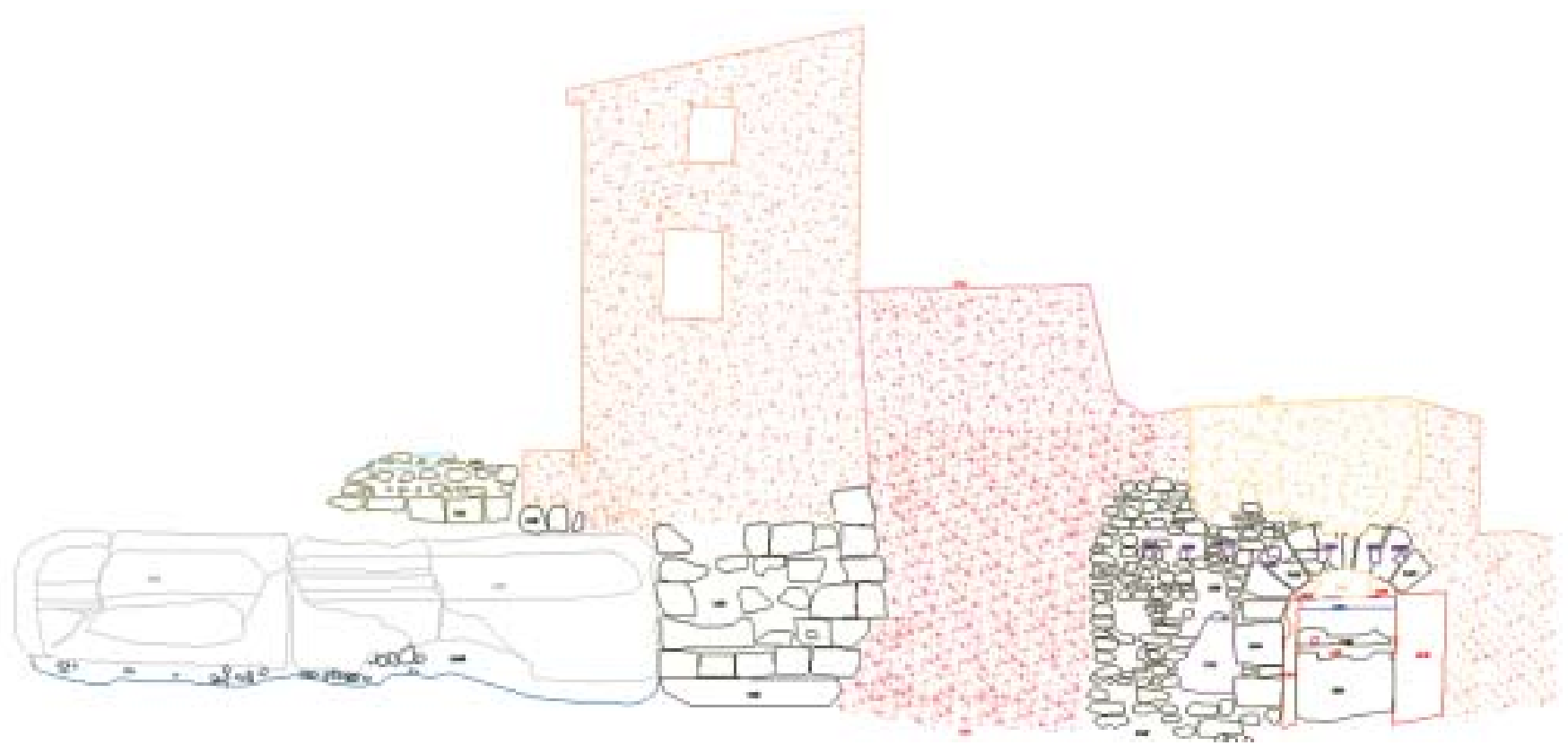

Fig. 3. Alzado de El Sequeral 


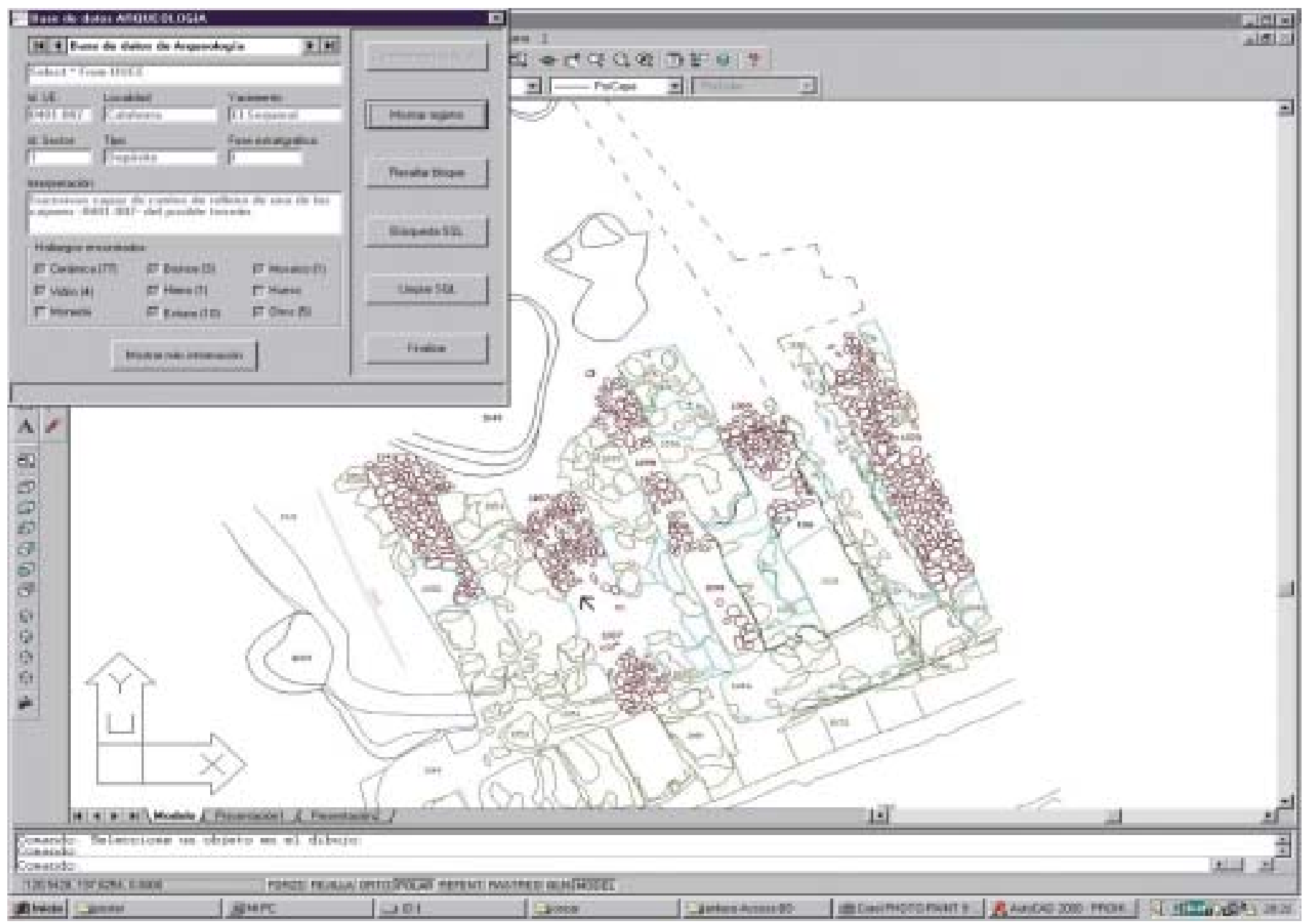

Fig. 4. Examen del conjunto de la información mediante el Sistema de Información Patrimonial creado

\section{RESULTADOS}

En lo referente a la documentación geométrica del proyecto se han conseguido resultados significativos en cuanto a la sistematización del registro de lo excavado, propiciando la posterior lectura y reinterpretación de todos los niveles arqueológicos significativos. En este sentido se ha utilizado de forma pionera el registro fotogramétrico digital, generando archivos de pares estereoscópicos debidamente documentados, referidos geométricamente y depositados de forma estructurada para la fácil recuperación de todos y cada uno de los elementos arqueológicos significativos de las excavaciones.

También se han diseñado, construido y depurado prototipos de elementos auxiliares para la toma fotográfica de pares estereoscópicos constituyendo una auténtica aportación instrumental a este tipo de trabajos, ya que suponen una mejora en el rendimiento, disposición y posibilidad de control de la toma fotográfica (Fig. 5). (VAlle Melón, LoPETEGUI GALARRAGA, 2001).

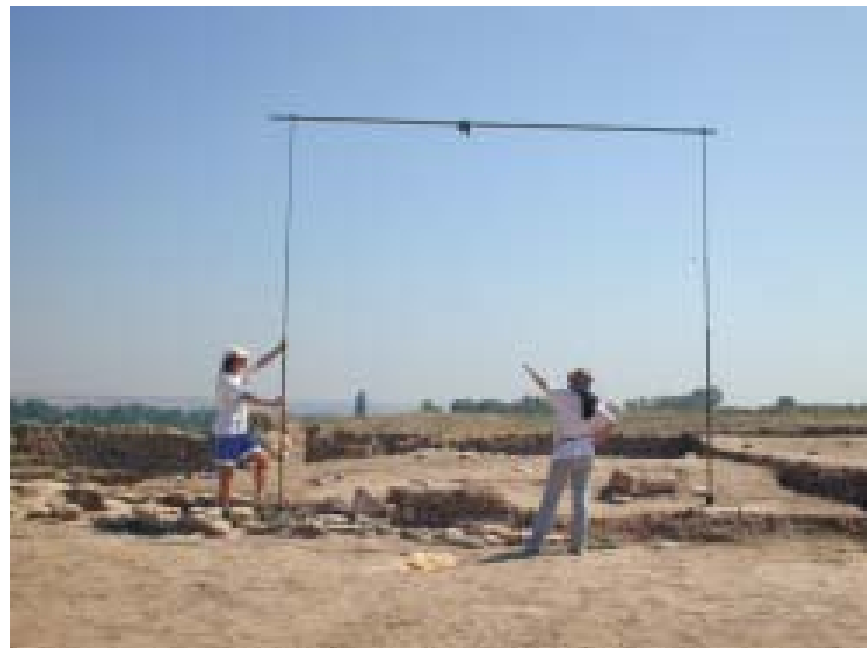

Fig. 5. Toma de pares estereoscópicos 
En el yacimiento de El Sequeral, durante el proceso de excavación pudieron identificarse estructuras que formarían parte de un lugar de habitación fechable en el siglo XVIII. Bajo éstos se documentaron unidades constructivas de época romana que conforman una única estructura. La lectura de los distintos paramentos —bloque de opus caementicium, lienzo de muralla y tirantes transversales- manifiestan relaciones estratigráficas muy estrechas.

El opus caementicium de dirección este-oeste - UE 1.048 - se asocia de manera directa con el lienzo de muralla -UE 1.122-, sin que pueda establecerse desde la lectura del alzado de los paramentos, las relaciones de anteroposterioridad existentes entre uno y otro. Tampoco se han podido contrastar tales relaciones en el plano horizontal, puesto que la unión entre ambos se produce fuera del sector excavado en esta campaña.

Este opus caementicium, que se encuentra fracturado y desplazado en parte, presenta un cuerpo conformado por fragmentos de piedra de factura homogénea procedentes del desmenuzamiento de piedras calizas de mayor tamaño y argamasa de cal. La total compactación de los elementos tiene como resultado un conglomerado de alta solidez y durabilidad.

En el bloque puede diferenciarse una zona inferior de factura descuidada que conformaría la cimentación propiamente dicha. Más arriba existe otro tramo que presentaba una cara alisada que reflejaba una elaboración mediante la técnica del encofrado. En El Sequeral, las hiladas de opus quadratum del exterior -paramento sur- se habrían perdido por causas que desconocemos; tal vez por la degradación ambiental y antrópica, o quizá debido a una expoliación premeditada para la posterior reutilización de los sillares en edificaciones de épocas posteriores

Se propone por tanto, la existencia de un lienzo mural compuesto por un cuerpo interno de opus caementicium recubierto por sendos paramentos de opus quadratum y adelantado notablemente con respecto al lienzo de muralla.

Está claro que las unidades constructivas descritas hasta el momento formarían un único conjunto estructural y así parecen confirmarlo las estrechas relaciones estratigráficas establecidas entre ellas. Pero, tal conjunto se vería reforzado por otra combinación de elementos murales que se unen a él ayudándole a adaptarse al fuerte desnivel del terreno natural. Estos elementos presentan una disposición transversal al lienzo que tradicionalmente se ha considerado como parte de la muralla de la ciudad romana.

El resultado era una estructura que responde a un patrón de composición rítmico: una serie de paramentos de sillarejos de arenisca se disponen paralelos entre si y relati- vamente próximos uno de otro, el espacio resultante se rellenaba de cantos rodados cuidadosamente colocados en capas horizontales y trabados con tierra arcillosa, finalmente los extremos se cierran con un paramento de hormigón. Esta técnica constructiva responde a los denominados «muros de cajones». Según ésta, a mayor pendiente mayor cercanía de los tirantes, y El Sequeral es el punto de mayor pendiente del asentamiento calagurritano respecto al valle del Cidacos.

Queda así conformada una estructura compacta de planta originariamente cuadrangular, adelantada con respecto al eje de la muralla y a la que se adosaría por su lado oriental. Pero no hemos podido documentar la unión por el oeste con aquélla. La ausencia del paramento occidental apunta la posibilidad de un cambio de dirección en el trazado del sistema defensivo calagurritano justo en éste punto, aunque no ha sido posible confirmar este extremo al adentrarse parte de las unidades constructivas en un solar anexo al área de excavación.

Toda esta información lleva a plantear como hipótesis la existencia en El Sequeral de los restos de cimentación de una gran torre de estructura cuadrangular de carácter angular, compacta y maciza al menos hasta la banqueta de cimentación y adelantada con respecto al eje de la muralla a la que se adosa.

Las características constructivas, así como los materiales cerámicos recuperados en uno de los cajones refleja una cronología de la primera mitad del siglo I d.C. Podríamos por tanto asociar la erección de los elementos defensivos documentados en El Sequeral a las primeras décadas de la vida de Calagurris Iulia como municipium civium Romanorum. Seguirían en pleno funcionamiento durante el resto de los siglos imperiales e, incluso, durante gran parte del proceso histórico medieval de la ciudad. Muy probablemente la destrucción, intencionada o accidental, de este bastión de la muralla se produciría durante un momento concreto comprendido entre el siglo XIII y el siglo XVI. Así puede deducirse de los materiales cerámicos asociados a las unidades estratigráficas de amortización de las estructuras (IGUÁCEL DE LA CRUZ, 2001: 146-156).

\section{Bibliografía}

BARKER P.A., 1977, Technique of Archaeological Excavation, London. Carandini A., 1997, Historias en la tierra. Manual de excavación arqueológica, Barcelona.

HARRIS E.C., 1991, Principios de estratigrafía arqueológica, Barcelona. IGUÁCEl DE LA CRUZ P., 2001, El Sequeral. Nuevas aproximaciones al conocimiento de la muralla de Calagurris Iulia, Iberia, n. ${ }^{\circ}$ 4, pp. 145-161.

Valle Melón J.M., Lopetegui Galarraga A., 2001, Aportación de las técnicas cartográficas a la documentación de yacimientos arqueológicos. El modelo del proyecto Calagurris Iulia, Iberia, n. ${ }^{\circ}$ 4, pp. 175-180. 